\title{
Ability of two new thiazolidinediones to downregulate proinflammatory cytokines in peripheral blood mononuclear cells from children with asthma
}

\author{
Moacyr Jesus Barreto de Melo Rêgo ${ }^{1}$, Adriana Azoubel-Antunes ${ }^{1,2}$, Mariana Brayner-Cavalcanti \\ Freire Bezerra $^{1}$, Michelly Cristiny Pereira ${ }^{1}$, Juliana Cruz da Silva ${ }^{3}$, Thiago Ubiratan Lins e Lins ${ }^{1}$, \\ Emanuel Sávio Cavalcanti Sarinho², Cézar Augusto da Cruz Amorim³, Maria do Carmo Alves de \\ Lima $^{3}$, Marina Rocha Galdino-Pitta ${ }^{3}$, Ivan da Rocha Pitta ${ }^{3}$, Maira Galdino da Rocha Pitta ${ }^{\text {* }}$
}

${ }^{1}$ Laboratório de Imunomodulação e Novas Abordagens Terapêuticas (LINAT), Núcleo de Pesquisas em Inovação Terapêutica (NUPIT), Universidade Federal de Pernambuco (UFPE) Recife, PE, Brasil, ${ }^{2}$ Serviço de Alergia e Imunologia Clínica, Hospital das Clínicas, UFPE, Recife, PE, Brasil, ${ }^{3}$ Laboratório de Planejamento e Síntese de Fármacos (LPSF), NUPIT, UFPE, Recife, PE, Brasil

\begin{abstract}
Allergic asthma is a chronic, complex inflammatory disease of the airway. Despite extensive studies on the immunomodulation of T helper (Th) cell pathways (i.e., Th1 and Th2) in asthma, little is known about the effects of Th17 pathway modulation, particularly that involving peroxisome proliferator-activated receptors (PPARs). In response, two new thiazolidinedione derivatives - namely, LPSF-GQ-147 and LPSF-CR-35 were synthesized and evaluated for their immunomodulatory effects on Th17-related cytokines, including interferon $\gamma$ (IFN $\gamma$ ), interleukin IL-6, IL-17, and IL-22 in the peripheral blood mononuclear cells of asthmatic children. Both compounds were nontoxic even at high concentrations (i.e., $100 \mu \mathrm{M})$. The LPSF-CR-35 compound significantly reduced the levels of IL-17A $(p=.039)$ and $\operatorname{IFN} \gamma(p=.032)$ at $10 \mu \mathrm{M}$. For IL-22 and IL-6, significant reduction occurred at $100 \mu \mathrm{M}(p=.039$ and $p=.02$, respectively). Conversely, LPSF-GQ-147 did not significantly inhibit the production of the tested cytokines, the levels of all of which were more efficiently reduced by LPSF-CR-35 than methylprednisolone, the standard compound. Real-time polymerase chain reaction assay confirmed that LPSF-GQ-147 has significant PPAR $\gamma$ modulatory activity. Such data indicate that both LPSF-CR-35 and LPSF-GQ-147 are promising candidates as drugs for treating inflammation and asthma.
\end{abstract}

Keywords: Asthma. Th17-related cytokines. Thiazolidinedione derivative.

\section{INTRODUCTION}

Asthma is a chronic, complex inflammatory disease of the airway whose development requires many cells and their products, including mast cells, eosinophils, $T$ lymphocytes, macrophages, neutrophils, and epithelial cells (Langier, Sade, Kivity, 2012; Robinson, 2009). Regarding lymphocytes, the imbalance of T helper (Th) cells Th1 and Th2 has been relatively well characterized as a mechanism involved in the pathogenesis of allergic

\footnotetext{
*Correspondence: M. G. R. Pitta. Laboratório de Imunomodulação e Novas Abordagens Terapêuticas (LINAT), Núcleo de Pesquisas em Inovação Terapêutica (NUPIT), Universidade Federal de Pernambuco (UFPE). Rua Tereza Amélia s/n, Cidade Universitária, CEP: 50670-901, Recife - PE Brasil. Telephone: +558121267495; +5581996717788. E-mail:mgrpitta@gmail.com
}

asthma (Colavita, Reinach, Peters, 2000; Gibeon, Menzies-Gow, 2012; Oboki et al., 2008). By contrast, the role of the Th17 pathway as a novel proinflammatory CD4+ T effector cell in asthma etiology remains largely unclear (Cosmi et al., 2011).

In asthma, interleukin (IL)-17 performs its role in a crescent area of intense activity. Wong et al. (2009) have shown that asthmatic individuals have higher amounts of peripheral Th17 cells, CCR6 expression, and IL-23 and IL-22 production stimulated by peripheral blood mononuclear cells (PBMCs) than individuals without asthma. In this pathway, IL-6 and transforming growth factor beta (TGF- $\beta$ ) together induce the differentiation of naïve T cells into Th17 lymphocytes by activating transcription factor regulator and thereby becoming 
producers of IL-17A, IL-17F, IL-22, and IL-23, which are responsible for maintaining the Th17 phenotype (Ivanov et al., 2006). Although the Th17 pathway mediates protective actions in bacterial and fungal infections, in human autoimmune and inflammatory diseases it has deleterious effects that compromise individual's clinical evolution and is thus an outstanding target for experimental research (Korn et al., 2009; Weaver et al., 2007).

A possible therapeutic means to decrease proinflammatory cytokines involved in respiratory inflammatory diseases such as asthma is the modulation of immunoregulatory proteins such as peroxisome proliferator-activated receptor $\gamma(\operatorname{PPAR} \gamma)$ (Amato, Neves, 2012). Peroxisome proliferator-activated receptors (PPARs) are a family of ligand-activated transcription factors in the nuclear hormone receptor family and are related to retinoid, glucocorticoid, and thyroid hormone receptors (Montagner et al., 2011). PPAR $\gamma$, the most extensively studied PPAR subtype, is involved in several lung diseases, including lung fibrosis, pulmonary vascular diseases, acute lung injury, and lung cancer (Rabinovitch, 2010). PPAR $\gamma$ activation reduces the synthesis and release of immunomodulatory cytokines from many cell types, including macrophages and monocytes, that participate in the regulation of inflammatory and immune processes (Zenhom et al., 2011). Recently found evidence suggests that PPAR $\gamma$ plays important roles in regulating processes related to airway inflammation, airway remodeling, and airway hyper-responsiveness, which indicates that it and its ligand show potential for developing treatments for chronic airway inflammatory diseases (Shen et al., 2012). Thiazolidine-2,4-dione (TZD) is a well-characterized synthetic ring that acts as a PPAR $\gamma$ agonist and whose structure is responsible for most of its pharmacological effects, including antiinflammatory ones (Faine et al., 2011). In response, the anti-inflammatory properties of new synthesized TZDs called LPSF-CR-35 (3-(4-bromo-benzyl)-5-(3-bromobenzylidene)-thiazolidine-2,4-dione) and LPSF-GQ-147 (5-(4-chlorobenzylidene)-3-(3,4-dichlorobenzyl)thiazolidine-2,4-dione) were evaluated in PBMCs from pediatric asthmatic individuals, particularly regarding their immunomodulatory effect on Th17 pathway-related cytokines.

\section{MATERIAL AND METHODS}

\section{Synthesis and characterization}

The compounds LPSF-GQ-147 (Z)-5-(4chlorobenzylidene)-3-(3,4-dichlorobenzyl) thiazolidine- 2,4-dione (Figure 1, no. 5) and LPSF-CR-35 (Z)-3-(4bromobenzyl)-5-(3-bromobenzylidene) thiazolidine2,4-dione (Figure 1, no. 10) were obtained from Laboratório de Planejamento de Síntese de Fármacos at the Universidade Federal de Pernambuco in Pernambuco, Brazil, and were duly identified by the nuclear magnetic resonance of hydrogen as well as infrared (IR) and mass spectroscopy (MS). Figure 1 displays the synthetic route of both compounds. To synthesize LPSF-GQ-147, published chemical data regarding 3-(3,4-dichlorobenzyl) thiazolidine-2,4-dione (LPSF-GQ-142; Figure 1, no. 3; Bozdağ-Dündar et al., 2006) were used (not shown). Next, 1.0 eq of 3-(3,4-dichlorobenzyl) thiazolidine-2,4dione LPSF-GQ-142 (Figure 1, no. 3) and 1.0 eq of (Z)-ethyl 2-amino-3-(4-chlorophenyl) acrylate LPSF-IP-4 (Figure 1, no. 4) were refluxed in ethanol in the presence of piperidine and heated at $55^{\circ} \mathrm{C}$ for $3 \mathrm{~h}$. Afterward, the mixture was filtered and washed with water. White solid. $\mathrm{C}_{17} \mathrm{H}_{10} \mathrm{Cl}_{3} \mathrm{NO}_{2} \mathrm{~S}$. Mp: $156-7{ }^{\circ} \mathrm{C}$. Yield: $71 \%$. IR ( $\mathrm{KBr}$, $\left.\mathrm{cm}^{-1}\right)$ : 1,682 $(\mathrm{C}=\mathrm{O}), 1,738(\mathrm{C}=\mathrm{O}), 1,619(\mathrm{C}=\mathrm{C}), 1,339$ $(\mathrm{C}-\mathrm{N}) . \mathrm{H}^{1} \mathrm{NMR}(300 \mathrm{MHz}, \mathrm{DMSOd} 6) \delta 7.97(\mathrm{~s}, 1 \mathrm{H}$, $=\mathrm{CH}), 7.68-7.60$ (m, 6H, 3-Ar-H, 5, 6 pos., 5-Ar-H, 2, 3, 5, 6 pos.), 7.32 (s, 1H, 3-Ar-H, 2 pos.), 4.84 (s, 2H, CH2). Obtaining LPSF-CR-35 (Figure 1, no. 10) began by reacting thiazolidine-2,4-dione (Figure 1, no. 1), which was reacted with 1-bromo-4-(chloromethyl) benzene (Figure 1, no. 6) under basic conditions to obtain the intermediate 3-(4-bromobenzyl) thiazolidine-2,4-dione (Figure 1, no. 7) following the procedure of Brandao et al. (2004). Next, 2-cyano-3-(4-chlorophenyl)-acrylic acid ethyl ester (Figure 1, no. 4; Mourão et al., 2005) was synthesized through Knoevenagel condensation between 4-chlorobenzaldehyde and ethyl cyanoacetate. A Michael addition was performed by reacting the $(E)-3$ (3-bromophenyl)-2-ethoxyacrylonitrile (Figure 1, no. 9) with the intermediate 3-(4-bromobenzyl) thiazolidine-2,4dione (Figure 1, no. 7) to form the final compound LPSFCR-35 (Figure 1, no. 10) Reactions were monitored with analytical thin-layer chromatography in 60 F254 silica gel plates and visualized under ultraviolet light (254 nm). Melting points were determined with a Quimis 340 capillary melting point apparatus and were not corrected. Infrared spectra were recorded as $\mathrm{KBr}$ discs using a Bruker (IFS66) infrared spectrophotometer. ${ }^{1} \mathrm{H}$ nuclear magnetic resonance (NMR) spectra were recorded in a VMMRS 300 $\mathrm{MHz}$ Varian spectrometer using tetramethylsilane as the internal standard and DMSO-d6 as the solvent. Chemical shifts $(\delta, \mathrm{ppm})$ were assigned according to the internal standard signal of tetramethylsilane in DMSO-d6 $(\delta$, ppm). Coupling constants $(J)$ are reported in Hz. ${ }^{1} \mathrm{H}$ NMR spectra are reported in the following order: chemical shift, 
multiplicity, number and type of proton, and coupling constants. Mass spectra with MALDI-TOF Autoflex III (Bruker Daltonics, Billerica, MA, USA). Laser Nd:YAG, $355 \mathrm{~nm}$. Freq. laser: $100 \mathrm{~Hz}$. The derivative 3 (Figure 1) was isolated as a single isomer. X-ray crystallographic studies and ${ }^{13} \mathrm{C}$ NMR have demonstrated a preferred $Z$ configuration for 5-benzylidene-thiazolidinones (De Simone et al., 1995; Guarda et al., 2003; Handzlik et al., 2012; Karolak-Wojciechowska et al., 2009; Tan, Ang, Fong, 1986). The presence of the arylidene proton peak in ${ }^{1} \mathrm{H}$ NMR for the synthesized derivative (Z)-3-(4bromobenzyl)-5-(3-bromobenzylidene) thiazolidine-2,4dione (Figure 1, no. 10) confirmed the completion of the nucleophilic addition reaction. The IR spectrum of the compound showed characteristic peaks of the carbonile group and arilidene. For the preparation of (Z)-3-(4bromobenzyl)-5-(3-bromobenzylidene) thiazolidine2,4-dione (Figure 1, $\mathrm{n}^{\mathrm{o}} 10$ ), equimolar amounts of 3-(4-bromobenzyl) thiazolidine-2,4-dione (Figure 1, no. 7) and (E)-3-(3-bromophenyl)-2-ethoxyacrylonitrile of 200 and $165 \mathrm{mg}$, respectively, were reacted using absolute ethanol $(8 \mathrm{~mL})$ as the solvent and morpholine $(1 \mathrm{~mL})$ as the catalyst. The reaction mixture was heated to $50{ }^{\circ} \mathrm{C}$ for $8 \mathrm{~h}$ and afterward cooled to roacom temperature. The solid that precipitated out was filtered in a vacuum and washed with water and absolute ethanol. MF: $\mathrm{C}_{17} \mathrm{H}_{11} \mathrm{Br}_{2} \mathrm{NO}_{2} \mathrm{~S}$; MW: 450,8877; MP: 205- $6{ }^{\circ} \mathrm{C}$; yield: 86\%; Rf: $0.60 n$-hexane/ ethylacetate 8:2. IR ( $\left.v, \mathrm{~cm}^{-1} ; \mathrm{KBr}\right): 1,743(\mathrm{C}=\mathrm{O}), 1,679$ $(\mathrm{C}=\mathrm{O}), 1,609(\mathrm{C}=\mathrm{C}) .{ }^{1} \mathrm{H}$ NMR $\left(300 \mathrm{MHZ}, \mathrm{DMSO}-\mathrm{d}_{6}\right)$ : $4.81\left(\mathrm{~s}, 2 \mathrm{H}, \mathrm{CH}_{2}\right), 7.29(\mathrm{dt}, 1 \mathrm{H}, \mathrm{H}-\mathrm{Ar}, J=8.7 \mathrm{~Hz}), 7.49$ $(\mathrm{d}, 2 \mathrm{H}, \mathrm{H}-\mathrm{Ar}, J=7.8 \mathrm{~Hz}), 7.55(\mathrm{dt}, 1 \mathrm{H}, \mathrm{H}-\mathrm{Ar}, J=8.8 \mathrm{~Hz})$, 7.61 (d, 1H, H-Ar, J=7.8 Hz), 7.70 (m, 1H, H-Ar), 7.87 (t, $1 \mathrm{H}, \mathrm{H}-\mathrm{Ar}, J=1.8 \mathrm{~Hz}), 7.96$ (s, $1 \mathrm{H},-\mathrm{CH}=)$. MS (m/z) relative intensity: expected value $[\mathrm{M}]^{+} 450.887$, found value $(\mathrm{M}+\mathrm{H})^{+1} 451.785$.

\section{Cell collection}

\section{Spleen}

The spleens of 30-d-old male mice BALB/c $(n=5)$ were obtained and maintained in the Laboratory of Immunopathology Keizo Asami (UFPE) following the recommendations of the Ethics Committee on Experimental Animal Research of UFPE.

Each spleen was aseptically removed and placed in a Petri dish containing RPMI-1640 (Gibco). In a vertical flow, each spleen was transferred to another Petri dish and washed in RPMI-1640 medium. The cell suspension obtained from each spleen was filtered in a $40-\mu \mathrm{m}$ nylon cell strainer (BD FalconTM) and transferred to conical centrifuge tubes (Falcon). The splenocytes were centrifuged with RBC lysis buffer $1 \times$ (eBiosciences) for incubation and resuspended on RPMI-1640 (Sigma) medium supplemented with $10 \%$ fetal bovine serum, $10 \mathrm{mM}$ of 4-(2-hydroxyethyl)-1-piperazine-ethanesulfonic acid (Gibco), and $200 \mathrm{U} / \mathrm{mL}$ of penicillin-streptomycin (Gibco). Cell viability was determined by using trypan blue exclusion with $0.4 \%$ trypan blue (Sigma); samples were used only when viability exceeded $98 \%$.

\section{Peripheral blood mononuclear cells (PBMCs)}

PBMCs were isolated from the blood of healthy donors $(n=15)$ aged $6-17$ years old and asthmatic patients, following their informed consent to participate in the study. The recruitment of those patients was conducted at the Division of Pediatric Allergy at the Hospital das Clínicas at UFPE. Forty-two participants 6-20 years old had been diagnosed with moderate $(n=27)$ or severe $(n=15)$ persistent asthma according to the Global Initiative for Asthma (2009). Patients who presented with

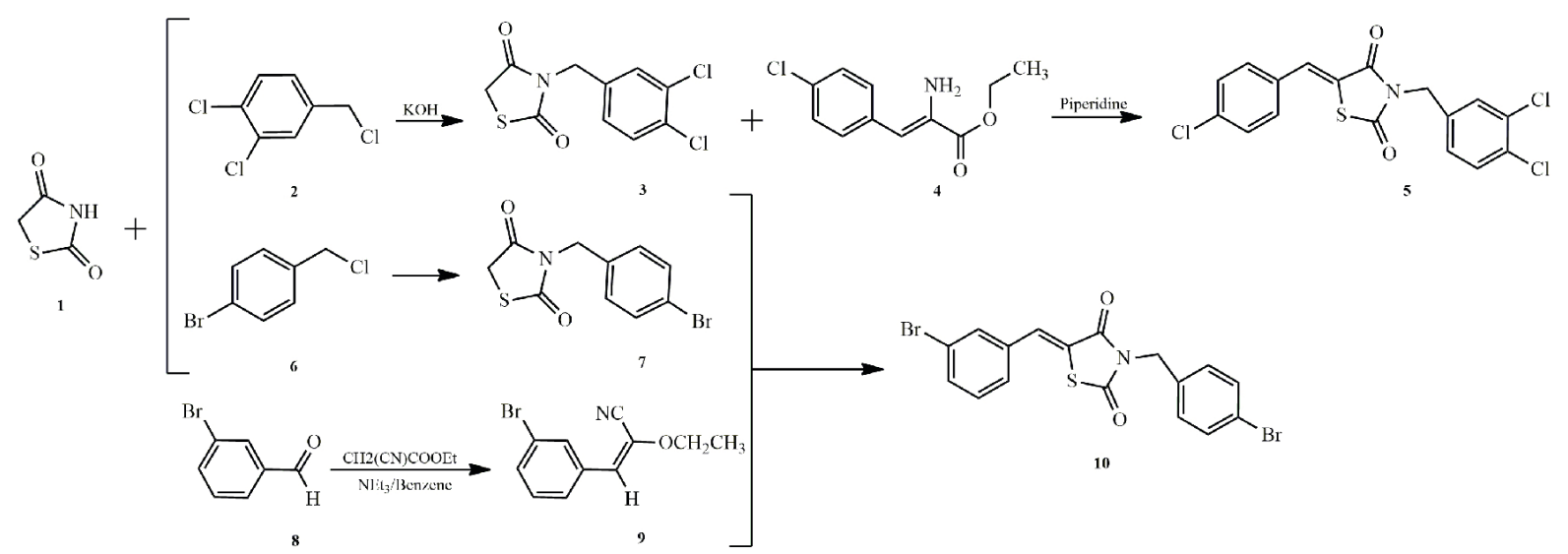

FIGURE 1 - Synthetic route for compounds LPSF/GQ-147 (Z)-5-(4-chlorobenzylidene)-3-(3,4-dichlorobenzyl) thiazolidine-2,4dione ( $\mathrm{n}^{\mathrm{o}} 5$ ) and LPSF/CR-35 (Z)-3-(4-bromobenzyl)-5-(3-bromobenzylidene) thiazolidine-2,4-dione ( $\left.\mathrm{n}^{\mathrm{o}} 10\right)$. 
atopic dermatitis, history of food allergy, autoimmune disease, immunodeficiency, infection, or cancer were excluded. The most revelant clinical and laboratorial parameters are presented in Table I.

TABLE I - Demographic, clinical and laboratory data of asthma patients

\begin{tabular}{|c|c|c|}
\hline & ASTHMA & CONTROLS \\
\hline Number of patients & 42 & 34 \\
\hline Age (years) & 12.7 & 11.7 \\
\hline Mean (range) & $8-21$ & $6-17$ \\
\hline \multicolumn{3}{|l|}{ Sex } \\
\hline Female & 17 & 16 \\
\hline Male & 25 & 18 \\
\hline \multicolumn{3}{|l|}{ Classification } \\
\hline SPA & 15 & \\
\hline MPA & 27 & \\
\hline \multirow[t]{2}{*}{ FEV1\% predicted } & SA:75.5 & \\
\hline & MPA: 88.0 & \\
\hline IgE level $\left(\mathrm{ng} \mathrm{mL} \mathrm{m}^{-1}\right)^{1}$ & 1347 & \\
\hline \multicolumn{3}{|l|}{ Allergen-Specific IgE } \\
\hline Positive & 29 & \\
\hline Negative & 13 & \\
\hline \multirow[t]{2}{*}{ ACT Score } & SPA: 15.57 & \\
\hline & MPA:12 & \\
\hline
\end{tabular}

FEV, forced expiratory volume; ACT, Asthma Control Test; SPA, severe persistent asthma; MPA, Moderate persistent asthma.

PBMCs were obtained by centrifugation with a Ficoll-PaqueTM Plus (GE Healthcare Bio-Sciences) centrifuge with a density $1.077 \mathrm{~g} / \mathrm{mL}$ and resuspended in RPMI 1640 medium (Gibco) supplemented with $10 \%$ fetal bovine serum (Gibco), $10 \mathrm{mM}$ of 4-(2-hydroxyethyl)-1piperazine-ethanesulfonic acid (Gibco), and $200 \mathrm{U} / \mathrm{mL}$ of penicillin-streptomycin (Gibco). Cell viability was again determined by using trypan blue exclusion with $0.4 \%$ trypan blue (Sigma); samples were used only when viability exceeded $98 \%$. For the assays, PBMCs $\left(1 \times 10^{6}\right.$ cells $\left./ \mathrm{mL}\right)$ were stimulated or not with phorbol 12-myristate 13-acetate (PMA) + ionomycin and incubated for $48 \mathrm{~h}$ before treatment with LPSF-CR-35 at $10 \mu \mathrm{M}$ and $100 \mu \mathrm{M}$. Methylprednisolone was used as a positive control.

\section{Cytotoxicity assay}

Mice splenocytes and the PBMCs of healthy donors were incubated in the presence of compounds in different concentrations: 100 and $250 \mu \mathrm{M}$ for the splenocytes and 10 and $100 \mu \mathrm{M}$ for the PBMCs. Cytotoxicity was quantified in terms of the ability of living cells to reduce $(3-(4,5)$ dimethylthiazol-2-yl)-2,5-diphenyl tetrazolium bromide (MTT) to an insoluble colored formazan derivative. After $48 \mathrm{~h}$ in a $5 \% \mathrm{CO}_{2}$ air-humidified atmosphere at $37^{\circ} \mathrm{C}, 20 \mu \mathrm{L}$ of MTT solution $(0.5 \mathrm{mg} / \mathrm{mL}$ of phenol red-free RPMI medium) was added. After incubation for another $3 \mathrm{~h}$, the formed crystals were dissolved in $20 \%$ SDS, and absorbance intensity was measured by a microplate reader (BioTek EL808®) at $570 \mathrm{~nm}$. All experiments were performed in triplicate, and relative cell viability (\%) was expressed as a percentage relative to the vehicle-treated cells.

\section{Cytokine titration}

Cytokines present in culture supernatants were quantified by sandwich enzyme-linked immunosorbent assay (ELISA) according to the procedure recommended by the suppliers. The lower detection limits of IL-6, IL-17A, IL-22, and IFN $\gamma$ were $9.375 \mathrm{pg} / \mathrm{mL}$, $15.625 \mathrm{pg} / \mathrm{mL}, 31.25 \mathrm{pg} / \mathrm{mL}$ and $15.625 \mathrm{pg} / \mathrm{mL}$, respectively. Cytokines in the supernatants of splenocyte cultures were assayed with ELISA mouse kits according to the manufacturer's instructions. The lower detection limits were $7.8 \mathrm{pg} / \mathrm{mL}$ for IL-6 (BD Biosciences) and IL-22 (eBiosciences), $3.9 \mathrm{pg} / \mathrm{mL}$ for IL-17A (eBiosciences), and $15.6 \mathrm{pg} / \mathrm{mL}$ for IFN $\gamma$ (BD Biosciences).

\section{Quantitative real-time polymerase chain reaction}

To gauge the ability of the compounds to modulate PPAR $\gamma$ gene expression, PBMCs were used as models (Da Rocha Junior et al., 2013). Total RNA from the healthy cells was extracted using Trizol ${ }^{\circledR}$ (Life Technologies) in accordance with the manufacturer's instructions, and cDNA synthesis was achieved with 3-4 $\mu \mathrm{g}$ of total RNA using the High Capacity Archive kit (Applied Biosystems). PPAR $\gamma$ mRNA levels were measured by real-time polymerase chain reaction (RT-PCR) using the $18 \mathrm{~S}$ ribosomal gene as the internal standard. Standard TaqMan probes were Hs01115513_m1 for PPAR $\gamma$ and Hs03928990_g1 for 18S amplification. RT-PCR reactions were performed using an ABIPrism 7900HT sequence detection PCR machine (Applied Biosystems) according to the manufacturer's instructions. Relative gene expression was calculated by using the $2^{-\Delta \Delta \mathrm{CT}}$ method.

\section{Ethics}

The Animal Ethics Committee at the Biological Science Center at UFPE approved the experiments 
(no. 23076.025821/2013-01). Written informed consent was obtained from all participants or their parents. The study was approved by the Research with Humans Ethics Committee of the Health Science Center at UFPE (no. 479/10).

\section{Statistical analysis}

Results were analyzed using the nonparametric Wilcoxon matched pairs test; $p$ values exceeding .05 were deemed significant for PBMCs. The Mann-Whitney test was used to assess cytokines in mice splenocytes. All data were plotted and analyzed with GraphPad Prism 5.0 software. In all graphs, bars represent $M \pm S D$.

\section{RESULTS}

\section{Toxicity}

The non-toxic dose of LPSF-CR-35 was determined before anti-inflammatory properties were evaluated in
PBMCs and splenocytes. For splenocytes, LPSF-CR-35 presented $91.4 \%( \pm 5.07)$ viability after treatment with $100 \mu \mathrm{M}$ and $78 \%( \pm 6.4)$ viability after treatment with $250 \mu \mathrm{M}$. In PBMCs from healthy donors, cytotoxicity was also low, with $97.9 \%( \pm 3.35)$ viability at $10 \mu \mathrm{M}$ and $91.2 \%( \pm 4.2)$ viability at $100 \mu \mathrm{M}$. Afterward, LPSF-CR-35 anti-inflammatory activity in splenocytes at 10 and $100 \mu \mathrm{M}$ was screened by using a dose of $250 \mu \mathrm{M}$; samples with cell viability exceeding $20 \%$ were not used in subsequent experiments.

\section{Anti-inflammatory screening of splenocyte cultures}

Prior to using the newly synthesized compounds in PBMCs from asthmatic participants, splenocytes were screened to evaluate the possible immunomodulatory effect of LPSF-CR-35 by using concanavalin A (ConA) as the cell mitogen. Dose-response behavior occurred during IFN $\gamma$ (Figure 2A), IL-6 (Figure 2B), and IL-17A (Figure 2C) secretion when the cells were treated
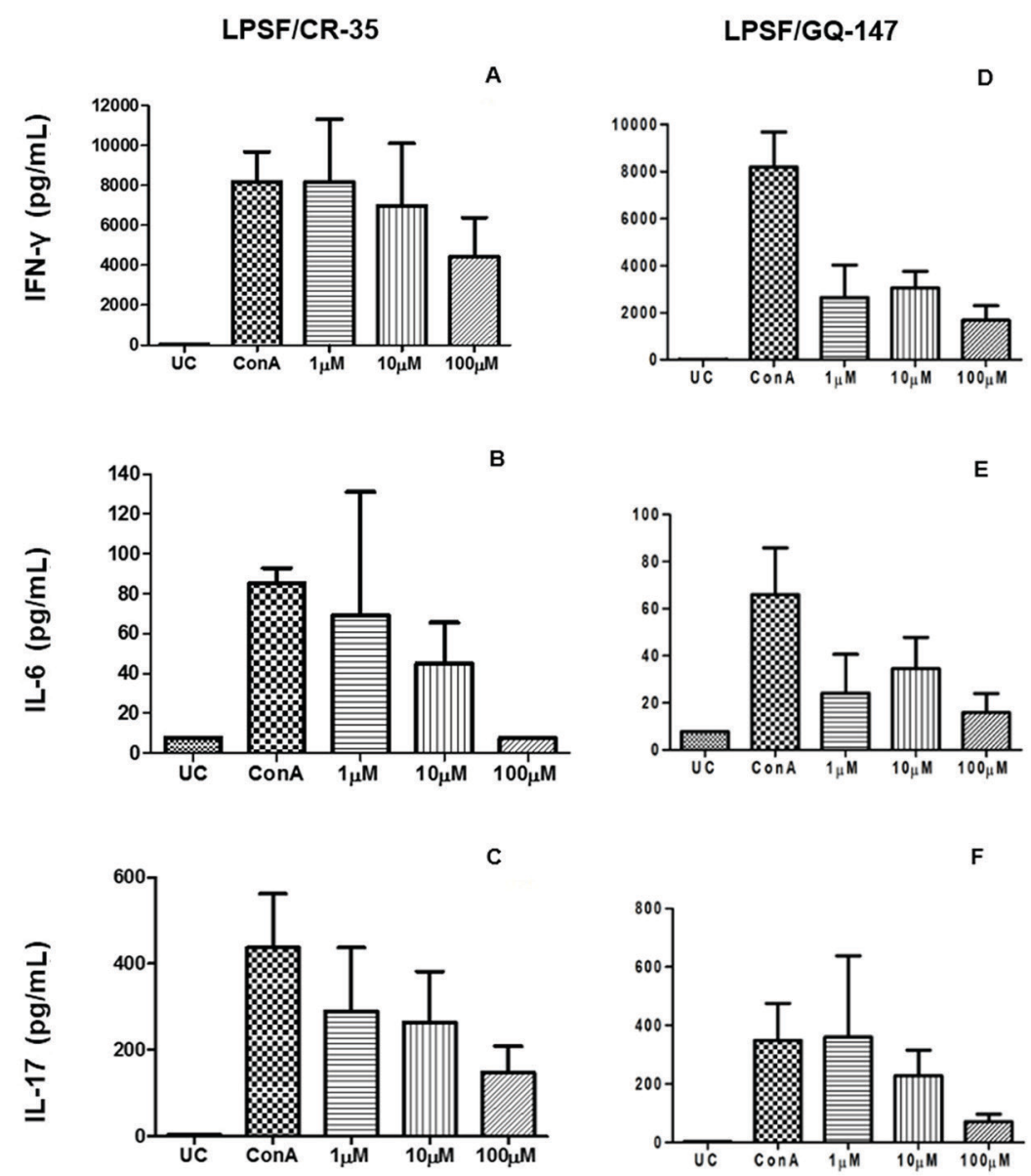

FIGURE 2 - Evaluation of pro-inflammatory cytokines release inhibition by LPSF/CR-35 and LPSF/GQ-147 in BALB/c mice splenocytes culture (n=5). IFN $\gamma(\mathrm{A}, \mathrm{B})$; IL6 (C, D); IL17 (E,F). UC = untreated cells; ConA = concanavalin A. 
with LPSF-CR-35 at 1, 10, and $100 \mu \mathrm{M}$. In relation to ConA-treated cells, despite a marked reduction to cytokine levels, particularly at $100 \mu \mathrm{M}$, no difference was significant. Similarly, the treatment of the culture medium with LPSF-GQ-147 decreased the levels of IFN $\gamma$ by threefold in relation to ConA-treated cells; the reduction was greater at $100 \mu \mathrm{M}$ (Figure 2D). For IL-6, the reduction level was by approximately 2.5 -fold and greater at $100 \mu \mathrm{M}$ (Figure 2E). By contrast, a dose response curve emerged for IL-17; cytokine levels were reduced by 3.5 -fold at $100 \mu \mathrm{M}$ (Figure 2F). There were no statistically significant results for the cytokine levels investigated.

Because both compounds inhibited proinflammatory cytokine levels in splenocytes, the new compounds were tested in PBMCs from pediatric asthmatic patients at 10 and $100 \mu \mathrm{M}$, both of which showed the best responses to splenocyte screening.

\section{Cytokine modulation by LPSF-CR-35 and LPSF-GQ-147 in PBMCs of asthmatic participants}

On a culture medium of PBMCs treated with LPSF-CR-35, levels of IFN $\gamma$ significantly reduced at $10 \mu \mathrm{M}(p=.032)$ and $100 \mu \mathrm{M}(p=.02)$ when compared to levels in the PMA-ionomycin condition (Figure 3A). By contrast, the reduction of IL-6 levels was significant only at $100 \mu \mathrm{M}(p=.02)$, as shown in Figure 3B. For IL-17A, the reduction induced by LPSF-CR-35 was significant at $10 \mu \mathrm{M}(p=.039)$ and became even more significant at $100 \mu \mathrm{M}(p=.015)$, as shown in Figure 3C. For IL-22,
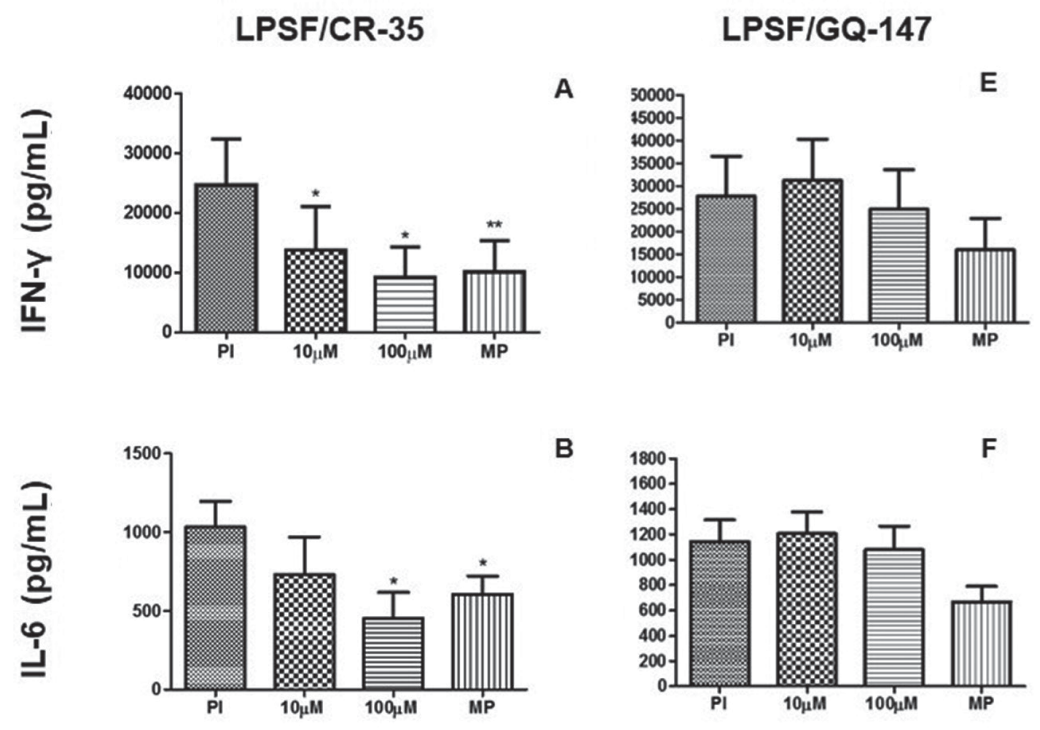

B
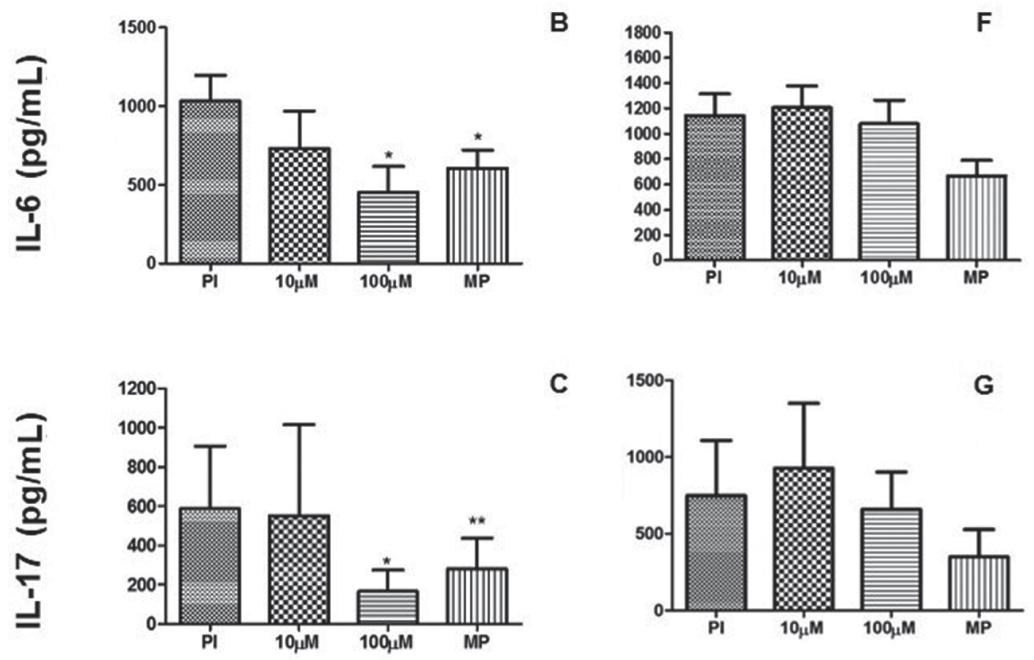

C
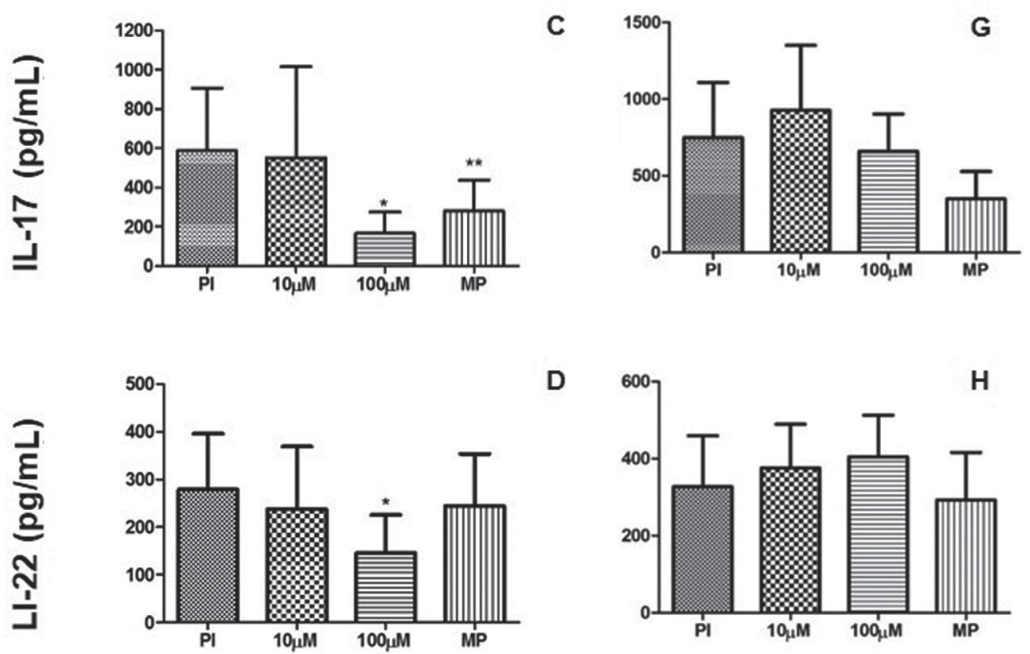

FIGURE 3 - Evaluation of pro-inflammatory cytokines release inhibition by LPSF/GQ-147 in PBMC culture from children asthmatic patients. IFN $\gamma(\mathrm{A}, \mathrm{B})$; IL-6 (C, D); IL-17A (E, F); IL-22 (G, H). PI = PMA + Ionomycin; MP = methylprednisolone. $(* p<0.05$ and $* \mathrm{p}<0.01)$. 
the reduction by LPSF-CR-35 was significant at $100 \mu \mathrm{M}$ $(p=.039)$ only (Figure 3D). Unlike LPSF-CR-35, LPSF-GQ-147 did not decrease IFN $\gamma$ (Figure 3E), IL-6 (Figure 3F), IL-17 (Figure 3G), or IL-22 (Figure 3H) secretion in PBMCs from asthmatic participants.

\section{Modulation of PPAR $\gamma$ mRNA expression by LPSF-GQ-147}

PPAR $\gamma$ expression was evaluated in human PBMCs from healthy individuals for $12 \mathrm{~h}$ in the absence or presence of the agonist rosiglitazone $(100 \mu \mathrm{M})$ as the positive control or LPSF-GQ-147 $(100 \mu \mathrm{M})$. As shown in Figure 4A, both treatments induced PPAR $\gamma$ expression in PBMCs, although LPSF-GQ-147 resulted in a greater increase in expression $(p=.0828)$.

The in vitro ability of PMA, used as a standard stimulus, and ionomycin to directly affect PPAR $\gamma$ expression in the absence or presence of PPAR $\gamma$ agonists was also analyzed. As shown in Figure 4B, LPSF-GQ-147 significantly reduced PPAR $\gamma$ expression in PMA-ionomycin-induced cytokine secretion in PBMCs $(p=.03)$, as did rosiglitazone $(p=.01)$.

\section{DISCUSSION}

Asthma is characterized by the overproduction of cytokines such as IL-17A and IL-22, released by Th17 lymphocytes differentiated by IL- 6 and TGF- $\beta$ induction (Ivanov et al., 2006), as has been extensively studied in pursuit of new anti-inflammatory drugs. The study presented here described a new TZD able to decrease levels of IL-17A, IL-6, and IFN- $\gamma$ in vitro and levels of IL-22 more effectively than methylprednisone.

The TZD ring is responsible for many pharmacological effects, including antitumor and anti-inflammatory ones (Faine et al., 2011). In inflammatory diseases, the ring acts as a PPAR $\gamma$ agonist, whose activation allows the reduction in the synthesis and release of immunomodulatory cytokines from many cells related to airway inflammation, airway remodeling, and airway hyper-responsiveness (Shen et al., 2012; Zenhom et al., 2011).

In addition to its anti-inflammatory role, the TZD ring allows the introduction of many substituents, which recommends its use as a framework for developing novel compounds (Shen et al., 2012). In LPSF-CR-35, the substituent bromobenzylidene may increase the antiinflammatory action given its high electronegativity that allows stronger binding with the PPAR $\gamma$ receptor.

Dai et al. (2011) observed similar behavior in the presence of chlorobenzylidene in andrographolide derivatives, since both molecules presented similar electronegativity. Although the present study involved in vitro analyses only, Iwakura et al. (2011) demonstrated that, in a murine model, PPAR $\gamma$ agonists suppress IL-17 expression in the lungs, which suggests that LPSF/GQ-147 would present the same behavior in in vivo models; however, more data are needed to confirm that hypothesis. PPAR agonists may therefore be useful in treating inflammatory lung diseases, which should prompt increased interest in the receptors and the study of their role in within-airway allergic diseases (Asaka et al., 2011).

Among other results, a major reduction was observed in IL-17A levels, in which the concentration of
A

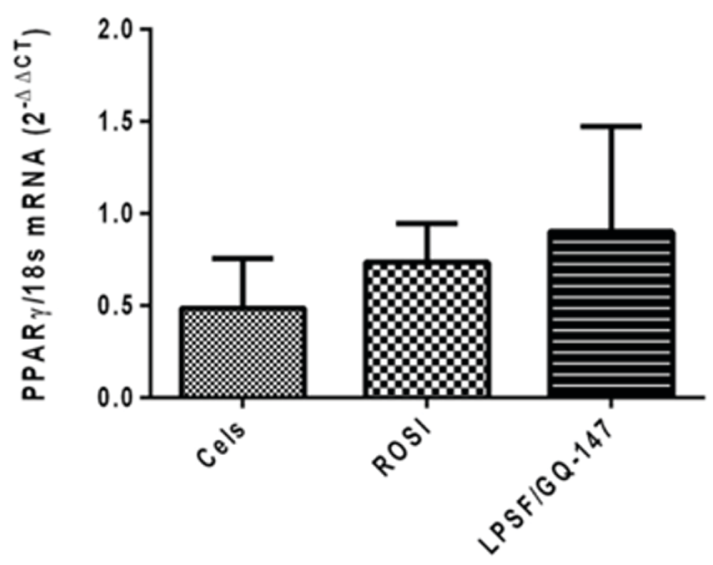

B

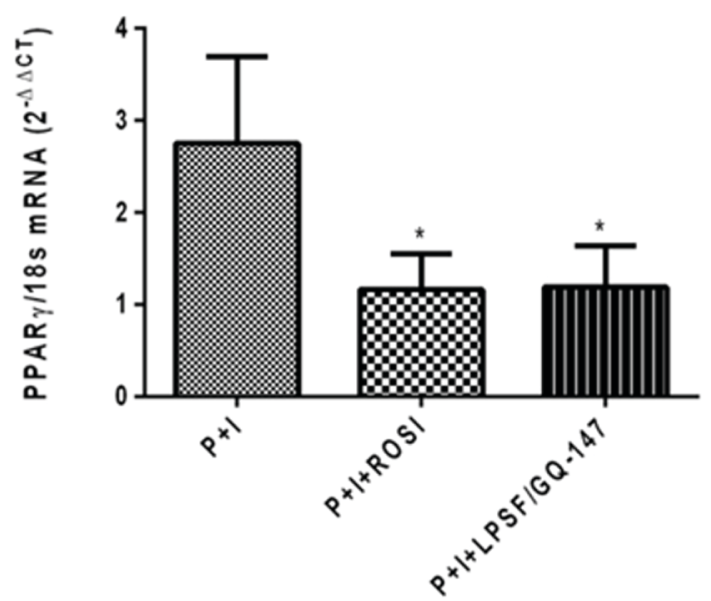

FIGURE 4 - PPAR $\gamma 18$ s mRNA ratio in PBMCs from healthy individuals. A. PPAR $\gamma$ mRNA in cells treated with Rosiglitazone and LPSF/GQ-147 compound at concentration of $100 \mu \mathrm{M}$. B. Iono and PMA enhance PPAR $\gamma$ expression and its agonists reduce significantly PPAR $\gamma$ mRNA antagonizing the effects of Iono and PMA $\left({ }^{*} \mathrm{p}<0.05\right)$. 
$100 \mu \mathrm{M}$ LPSF-CR-35 reduced the cytokines in the cells of asthmatic participants. That observation is interesting, because IL-17 has been strongly linked to chronicity in lung diseases, in which it stimulates innate immunity and induces neutrophilic airway inflammation, chiefly by stimulating immunoglobulin E production by human B cells mediated by IL-17A (Zenewicz et al., 2008).

The role of IL-22 in inflammatory diseases can be either pathological or tissue protective depending on the disease. Sonnenberg et al. (2010) demonstrated that IL$17 \mathrm{~A}$ can govern the proinflammatory-pathological versus tissue-protective properties of IL-22 in the lungs. They suggested that the presence of IL-17A is necessary for the proinflammatory role of IL-22 amid airway damage and inflammation, in which both ILs act synergistically by promoting chemokine expression and neutrophil recruitment. In addition, Liang et al. (2007) found that the administration of exogenous IL-22 was insufficient to promote neutrophil recruitment to the airway. Together, the studies suggest that LPSF-CR-35 could be used as an anti-inflammatory drug in asthma, because the newly developed TZD more effectively reduced the expression of both cytokines than methylprednisone.

IL-6 is an important regulator of CD4+ T cell differentiation that inhibits Th1 differentiation and promotes Th17 cell differentiation (Dienz, Rincon, 2009) and has thus been described as an inflammation marker in diseases such as rheumatoid arthritis and asthma (Kishimoto, 2010). Recently, IL-6 was described as not only an inflammatory marker but also an active cytokine, and some studies have described a correlation between the presence of IL-6 in airways and impaired lung function, thereby suggesting its direct involvement in the pathogenesis and progression of the disease (Morjaria et al., 2011; Neveu et al., 2011). Because IL-6 is a potential target in asthma treatment, our results reinforce the importance of the newly developed TZD CR-35 as an anti-inflammatory agent.

The reduction of IL-17A, IL-6, IL-22, and IFN- $\gamma$ levels in asthmatic participants presented by LPSF-CR-35 confirms the anti-inflammatory role of the TZD in association with the bromobenzylidene substituent in different actions in the inflammatory pathway and highlights the importance of the newly developed TZD as a potential anti-inflammatory drug.

Interestingly, the compound was more effective at reducing IL-17A than IL-6, IL-22, and IFN $\gamma$ cytokines (Diehl, Rincón, 2002; Kumar et al., 2012). The reduction in IL-17A is important because research on mice has shown that IL-17 could trigger lung inflammation by stimulating innate immunity and induce neutrophilic airway inflammation, which are strongly linked to chronic inflammation (Iwakura et al., 2011).

Results show that LPSF-GQ-147 enhanced PPAR $\gamma$ expression in the absence of a stimulus. Palma (2012) found that the agonists 15d-PGJ, MTX, and methylprednisolone increased receptor expression in cells isolated from healthy donors (Palma et al., 2012). Earlier, Marx et al. (1998) observed that PMA-ionomycin enhanced PPAR $\gamma$ expression and that its agonists significantly reduced PPAR $\gamma$ mRNA, thereby possibly antagonizing the effects of PMA-ionomycin mitogens. PPAR $\gamma$ mRNA expression in U937 cells also increased during PMA-induced differentiation (Marx et al., 1998).

In addition to the intrinsic anti-inflammatory activity of the thiazolidine ring, the substituent chlorobenzylidene, present in LPSF-GQ-147, potentiates anti-inflammatory activity when introduced in some molecules (Dai et al., 2011), which partly explains the action of the molecule examined in the present study. Moreover, the other substituent from the molecule, dichlorobenzyl, appears in DG-041 as an antagonist from the EP3 receptor, which is the natural agonist of the inflammatory mediator prostaglandin E2 (Heptinstall et al., 2008).

\section{CONCLUSIONS}

These results present the newly developed TZD LPSF-CR-35 reduced the secretion of IL-17A, IL-22, IL-6, and IFN $\gamma$ in PBMCs from asthmatic children and that LPSF-GQ-147 modulated PPAR mRNA levels. Such findings indicate that both compounds are promising candidates for drugs to treat inflammation and asthma.

\section{REFERENCES}

Amato AA, Neves FAR. Idealized PPAR-Based therapies: lessons from bench and bedside. PPAR Res. 2012;(2012):ID978687.

Asaka C, Honda K, Ito E, Fukui N, Chihara J, Ishikawa K. Peroxisome proliferator-activated receptor- $\gamma$ is expressed in eosinophils in nasal polyps. Int Arch Allergy Immunol. 2011;155(suppl 1):57-63.

Bozdağ-Dündar O, Ceylan-Unlüsoy M, Verspohl EJ, Ertan R. Synthesis and antidiabetic activity of novel 2,4-thiazolidinedione derivatives containing a thiazole ring. Arzneimittelforschung. 2006;56(9):621-25.

Brandao SSF, Andrade AMC, Pereira DTM, Barbosa Filho JM, Lima MCA, Galdino SL, et al. A novel way of synthesis of 1,3,5trisubstituted-2- thioxoimidazolidinones. Heterocycl Commun. 2004;10(1):5-10. 
Colavita AM, Reinach AJ, Peters SP. Contributing factors to the pathobiology of asthma. The Th1/Th2 paradigm. Clin Chest Med. 2000;21(2):263-77.

Cosmi L, Liotta F, Maggi E, Romagnani S, Annunziato F. Th17 Cells: new players in asthma pathogenesis. Allergy. 2011;66(8):989-98.

Da Rocha Junior LF, Dantas AT, Duarte ALBP, Rego MJBM, Pitta IR, Pitta MGR. PPAR $\gamma$ agonists in adaptive immunity: what do immune disorders and their models have to tell us? PPAR Res. 2013:(2013):ID519724.

Dai G-F, Zhao J, Jiang Z-W, Zhu L-P, Xu H-W, Ma W-Y, et al. Anti-Inflammatory effect of novel andrographolide derivatives through inhibition of $\mathrm{NO}$ and PGE2 production. Int Immunopharmacol. 2011;11(12):2144-49.

De Simone CA, Zukerman-Schpector J, Pereira MA, Cuong LD, Pitta IR, Galdino SL, et al. 3-(4-Bromobenzyl)-5-(4Fluorobenzylidene)imidazolidine-2,4-Dione. Acta Crystallogr Sect C Cryst Struct Commun. 1995;51(12):2620-21.

Diehl S, Rincón M. The two faces of IL-6 on Th1/Th2 differentiation. Mol Immunol. 2002;39(9):531-36.

Dienz, Rincon. The effects of IL-6 on CD4 T cell response. Clin Immunol. 2009;130(1):27-33.

Faine LA, Rudnicki M, César FA, Heras BL, Boscá L, Souza ES, et al. Anti-inflammatory and antioxidant properties of a new arylidene-thiazolidinedione in macrophages. Curr Med Chem. 2011;18(22):3351-60.

Gibeon D, Menzies-Gow AN. Targeting interleukins to treat severe asthma. Expert Rev Respir Med. 2012;6(4):423-39.

Guarda VLM, Pereira MA, De Simone CA, Albuquerque JFC, Galdino SL, Chantegrel J, et al. Synthesis and structural study of arylidene thiazolidine and benzothiazine compounds. Sulfur Lett. $2003 ; 26(1): 17-27$.

Handzlik J, Szymańska E, Wójcik R, Dela A, Jastrzebska-Wiesek M, Karolak-Wojciechowska J, et al. Synthesis and SAR-study for novel arylpiperazine derivatives of 5-arylidenehydantoin with $\alpha 1$-adrenoceptor antagonistic properties. Bioorg Med Chem. 2012;20(14):4245-57.
Heptinstall S, Espinosa DI, Manolopoulos P, Glenn JR, White AE, Johnson A, et al. DG-041 inhibits the EP3 prostanoid receptor - a new target for inhibition of platelet function in atherothrombotic disease. Platelets. 2008;19(8):605-13.

Ivanov II, McKenzie BS, Zhou L, Tadokoro CE, Lepelley A, Lafaille JJ, et al. The orphan nuclear receptor RORgammat directs the differentiation program of proinflammatory IL-17+ T helper cells. Cell. 2006;126(6):1121-33.

Iwakura Y, Ishigame H, Saijo S, Nakae S. Functional specialization of interleukin-17 family members. Immunity. 2011;34(2):149-62.

Karolak-Wojciechowska J, Szymańska E, Mrozek A, KiećKononowicz K. crystallographic and spectroscopic studies of 5-arylidene-2-amino-imidazol-4-ones. J Mol Struct. 2009;930(1-3):126-34.

Kishimoto T. IL-6: from its discovery to clinical applications. Int Immunol. 2010;22(5):347-52.

Korn T, Bettelli E, Oukka M, Kuchroo VK. IL-17 and Th17 cells. Ann Rev Immunol. 2009;27(1):485-517.

Kumar RK, Yang M, Herbert C, Foster PS. Interferon- $\Gamma$, pulmonary macrophages and airway responsiveness in asthma. Inflamm Allergy Drug Targets. 2012;11(4):292-97.

Langier S, Sade K, Kivity S. Regulatory T cells in allergic asthma. Isr Med Assoc J. 2012;14(3):180-83.

Liang SC, Long AJ, Bennett F, Whitters MJ, Karim R, Collins $\mathrm{M}$, et al. An IL-17F/A heterodimer protein is produced by mouse Th17 cells and induces airway neutrophil recruitment. J Immunol. 2007;179(11):7791-99.

Marx N, Sukhova G, Murphy C, Libby P, Plutzky J. Macrophages in human atheroma contain PPARgamma: differentiationdependent peroxisomal proliferator-activated receptor gamma(PPARgamma) expression and reduction of MMP-9 activity through PPARgamma activation in mononuclear phagocytes in vitro. Am J Pathol. 1998;153(1):17-23.

Montagner A, Rando G, Degueurce G, Leuenberger N, Michalik L, Wahli W. New insights into the role of PPARs. Prostaglandins, Leukot. Essent Fat Acids. 2011;85(5):235-43.

Morjaria JB, Babu KS, Vijayanand P, Chauhan AJ, Davies DE, Holgate ST. Sputum IL-6 concentrations in severe asthma and its relationship with FEV1. Thorax. 2011;66(6):537. 
Mourão RH, Silva TG, Soares ALM, Vieira ES, Santos JN, Lima MCA, et al. Synthesis and biological activity of novel acridinylidene and benzylidene thiazolidinediones. Eur J Med Chem. 2005;40(11):1129-33.

Neveu,WA, Bernardo E, Allard JL, Nagaleekar V, Wargo MJ, Davis RJ, et al. Fungal Allergen [beta]-Glucans Trigger p38 mitogen-activated protein kinase-mediated IL-6 translation in lung epithelial cells. Am J Respir Cell Mol Biol. 2011;45(6):1133-41.

Oboki K, Ohno T, Saito H, Nakae S. Th17 and allergy. Allergol Int. 2008;57(2):121-34.

Palma A, Sainaghi PP, Amoruso A, Fresu LG, Avanzi G, Pirisi $\mathrm{M}$, et al. Peroxisome proliferator-activated receptor-gamma expression in monocytes/macrophages from rheumatoid arthritis patients: relation to disease activity and therapy efficacy-a pilot study. Rheumatology (Oxford). 2012;51(11):1942-52.

Rabinovitch M. PPARgamma and the pathobiology of pulmonary arterial hypertension. Adv Exp Med Biol. 2010;661:447-58.

Robinson DS. Regulatory T cells and asthma. Clin Exp Allergy. 2009;39(9):1314-23.

Shen Y, Chen L, Wang T, Wen F. PPAR As a potential target to treat airway mucus hypersecretion in chronic airway inflammatory diseases. PPAR Res. 2012;(2012):ID 256874.
Sonnenberg GF, Nair MG, Kirn TJ, Zaph C, Fouser LA, Artis D. Pathological versus protective functions of IL-22 in airway inflammation are regulated by IL-17A. J Exp Med. 2010;207(6):1293-1305.

Tan, S-F, Ang K-P, Fong Y-F. (Z) - and (E)-5Arylmethylenehydantoins: spectroscopic properties and configuration assignment. J Chem Soc Perkin Trans 2. 1986;12:1941-1944.

Weaver CT, Hatton RD, Mangan PR, Harrington LE. IL-17 Family cytokines and the expanding diversity of effector T cell lineages. Ann Rev Immunol. 2007;25:821-52.

Wong CK, Lun SWM, Ko FWS, Wong PTY, Hu SQ, Chan IHS, et al. Activation of peripheral Th17 lymphocytes in patients with asthma. Immunol Invest. 2009;38(7):652-64.

Zenewicz LA, Yancopoulos GD, Valenzuela DM, Murphy AJ, Stevens S, Flavell RA. Innate and adaptive interleukin-22 protects mice from inflammatory bowel disease. Immunity. 2008;29(6):947-57.

Zenhom M, Hyder A, De Vrese M, Heller KJ, Roeder T, Schrezenmeir J. Prebiotic oligosaccharides reduce proinflammatory cytokines in intestinal Caco-2 cells via activation of PPARgamma and peptidoglycan recognition protein $3^{\wedge} 1-3$. J Nutr. 2011;141(5):971-77.

Received for publication on $01^{\text {st }}$ February 2017 Accepted for publication on $30^{\text {th }}$ August 2017 